\title{
Syringomyelia: Report of a Clinical Case and Bibliographical Review
}

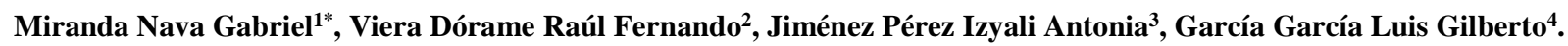 \\ ${ }^{1}$ Neurólogo Jefe Del Servicio de Neurología Del Hospital Militar Regional de \\ especialidades de Guadalajara, México. \\ ${ }^{2}$ Neurocirujano Jefe Del Servicio de Neurocirugía Del Hospital Militar Regional de especialidades de Guadalajara, \\ México. \\ ${ }^{3}$ Hospital Militar Regional de Especialidades Médicas de Guadalajara, México. \\ ${ }^{4}$ Hospital Militar Regional de Especialidades Médicas de Guadalajara, México.
}

*Corresponding Author: Miranda Nava Gabriel, Neurólogo Jefe del Servicio de Neurología del Hospital Militar Regional de especialidades de Guadalajara, México

Received date: December 03, 2019; Accepted date: December 27, 2019; Published date: January 03, 2020

Citation: Miranda N Gabriel, Viera Dórame Raúl Fernando, Jiménez Pérez Izyali Antonia, García García Luis Gilberto. (2020) Syringomyelia: Report of a Clinical Case and Bibliographical Review. J. Neuroscience and Neurological Surgery. 6(1); DOI:10.31579/2578-8868/109

Copyright: () 2020 Miranda Nava Gabriel, This is an open-access article distributed under the terms of The Creative Commons Attribution License, which permits unrestricted use, distribution, and reproduction in any medium, provided the original author and source are credited.

Abstract
Introduction
Syringomyelia is a pathological involvement of the spinal cord, which consists of a central cavitation, which mainly
affects the cervical area. In $90 \%$ of cases, it may be closely related to Chiari disease, however, there are other alterations
such as intra or extramedullary tumor, trauma, hydrocephalus, among others that can cause syringomyelia as well. The
diagnosis is completed with imaging studies (MRI). The treatment is usually surgical in most cases, as long as the patient
is a candidate for it. However, there are other alternatives with promising results.
Clinical Case: A 47 -year-old female patient, who goes to the outpatient clinic, referring pain in the upper extremities,
mainly in the right, irradiated to the dorsal region, in addition to presenting other signs and symptoms such as
tachycardia, medium intensity precordial pain, headache, nausea and dizziness As a pathological personal history, the
patient reports having suffered seizures during childhood, in addition to being hit by a truck with an evolution time of
15 years.
Conclusions: with the studies obtained and the evaluation of the patient, the diagnosis of syringomyelia associated
with Chiari is reached. The patient is followed up and scheduled for neurosurgical treatment due to the presence of
symptoms.
Key words: syringomyelia; Adults; spinal cord compression; magnetic resonance; chiari; trauma

Introduction

Syringomyelia is a generic term referring to a disorder in which a cyst or a tubular cavity is formed within the spinal cord. This cyst is known as syrinx or "syrinx." It is necessary to differentiate it from the term hydromielia that refers to a dilation of the central medullary canal [1].

It is a unique pathological entity of the spinal cord that consists of a generally central cavitation and preferentially affects the cervical cord. This pathology is progressive and degenerative presenting fluctuating conditions ranging from severe worsening in 5 to 10 years to a slow progression of 30 to 40 years or more [3].

In $90 \%$ of cases, syringomyelia is associated with Chiari type 1 malformation, while the remaining $10 \%$ includes syringomyelia without association with Chiari1 (idiopathic), being able to be secondary to intramedullary tumor, spinal trauma, compression by extramedullary tumor, spinal infarction and hydrocephalus [7].

Chiari disease is characterized by an anatomical abnormality that causes the lower part of the cerebellum (cerebellar tonsils) to protrude from its normal position at the back of the head towards the cervical region (or neck) of the spinal canal. In the case of trauma or tumor complication, the syrinx or cyst is formed in a segment of the spinal cord, it begins to expand, subsequently causing symptoms, with pain being the main one. If the involvement gets to involve the brain stem (syringobulia), there may be changes in vital functions such as breathing and heart rhythm $[2,3,5]$.

The clinical picture usually begins in the third decade of life. In the beginning it can manifest itself inconclusively with pain in the posterior cervical area, being able to be triggered by physical efforts or Valsalva maneuvers and subsequently presenting hypoesthesia mainly in the upper limbs, as well as motor deficit in them, with minimal involvement in the lower limbs [5].

The diagnosis is based on a good history, as well as a complete physical examination, emphasizing neurological functions. Subsequently, imaging studies can be requested, with magnetic resonance imaging being the study of choice in these cases, since it allows us to see in detail the structures to be studied, as well as the alterations that could occur, mainly in the cerebrospinal fluid and spinal cord [7]. 
The treatment in patients with this pathology is usually very variable; Surgery is generally recommended, in order to provide more space for the cerebellum (Chiari malformation) at the base of the skull and upper neck, without entering the brain or spinal cord. This allows the primary cavity to flatten or disappear and with it the symptoms improve [2, 4].

Pharmacological treatment has no curative value, radiation is used infrequently and produces few benefits. In the absence of symptoms, no treatment is generally granted [6].

There must be a protocol with which to choose the candidate patients for surgery, they must have significant symptoms such as severe chronic pain, limitation in daily activities, respiratory problems, persistent seizures, and adequate surgical risk by medicine internal, comorbidities denied or under treatment. All this in order to always assess the risk-benefit of the patient [6].

\section{Clinical case:}

Female patient, in name referred to by the following acronym MCGD of 47 years of age, who enters the emergency department due to a seizure crisis, presented at 03: $00 \mathrm{hrs}$ at home, approximately three minutes long with loss of consciousness, referred by his daughter who witnessed the act; has a slight frontal contusion. The patient reports having a history of seizures in childhood, without showing up since age 19. Already in the emergency department, physical examination is aware, oriented, without neurological deficit, at that stable moment; vital signs within normal parameters, isoreflective pupils, cylindrical neck without palpable adenomegalies, cardiac area without added noises, well-ventilated lung fields, globose abdomen at the expense of adipose panicle, depressible, without pain on superficial or deep palpation, upper limbs with decrease of strength, increased osteotendinous reflexes, capillary filling of 2 seconds, rest of the physical examination without alterations. He is diagnosed with "seizures, not classified elsewhere." As well as its respective management with hydration, safety and antiepileptic position, it is kept under observation, and subsequently discharged from the emergency department by appointment in the outpatient clinic for the neurology service.

Later he comes to his consultation by the neurology service of the Military Hospital of Medical Specialties of Guadalajara, for referring pain and alteration of the force in both upper extremities. The patient reports that the pain is more intense in the right upper limb and in the cervical-dorsal region. In addition to presenting tachycardias, precordial pain of medium intensity, headache, nausea and dizziness, with low response to analgesic treatment.

Upon questioning, the patient refers to the history of having been hit by a 15-year-old truck, currently with painful sequelae in the upper right limb and lateral region of the ipsilateral neck. An imaging study (magnetic resonance imaging) is performed, which shows data of syringomyelia and cervical osteoarthritis.

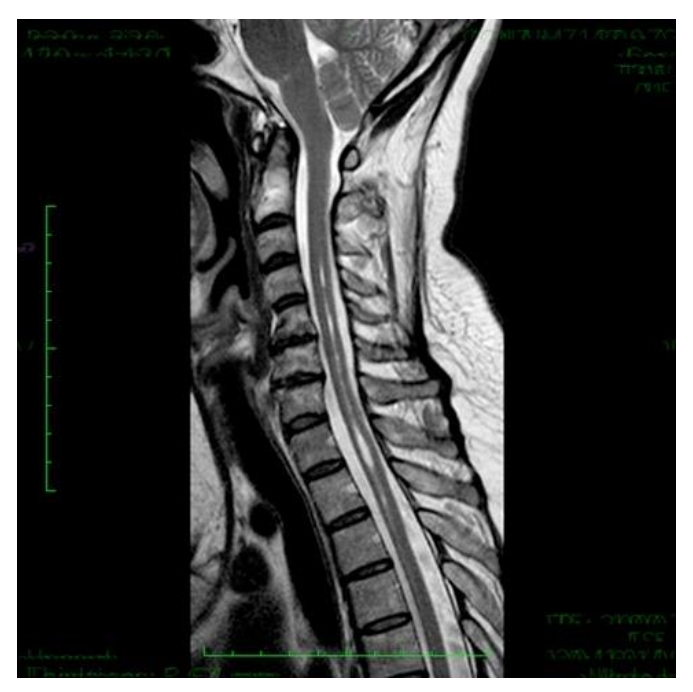

Figure 1: magnetic resonance imaging, sagittal section, with data suggestive of osteodegenerative disc disease, with loss of the height of the vertebral bodies of C5, C6 and C7; as well as dehydration of the intervetebral discs C5-C6, C6-C7 and C7-T1.

In addition to hyperintense intramedullary cystic cavity in T2 weighting of magnetic resonance, from intramedullary C4-T2 level. Presenting decrease of cerebellar tonsils that obstruct the magician foramen more than $5 \mathrm{~mm}$. (Courtesy of the Regional Military Hospital of Medical Specialties of Guadalajara) the patient was asked to consult with the neurosurgery service to see the possibility of undergoing a surgical procedure due to chronic cervicalgia. Continue attending a consultation by the Neurology service for its management and evolution, as well as the rehabilitation service. It is currently waiting for surgical time.

\section{Discussion}

In this case, it is suspected as the first possibility that syringomyelia may be secondary to or related to Chiari disease. The plan will be to propose neurosurgical management, prior to which a 4-limb electromyography should be performed to corroborate the etiology of neurological damage. Electromyography is a study that will measure the conduction velocity of nerve transmission to infer the etiological origin of the damage if it exists in this patient [8].

This relationship with Chiari disease is coupled with the decrease in cerebellar tonsils, which allow us to suspect secondary damage to the 
patient's disease. In cabinet studies conducted by the convulsive crisis, an intramedullary hyperintense image from $\mathrm{C} 4$ to $\mathrm{T} 3$, suggestive of syringomyelia, was evidenced as an incidental finding. It should be noted that this lesion is already producing significant neurological damage in our patient, however, the diagnosis was obtained through an incidental finding.

Conclusions:

It is recommended to expand the study and knowledge of this common pathology, but underdiagnosed, in order to provide more and better treatments to patients with this disease.

This avoids the progression of the disease and promotes a speedy recovery that generates an increase in the quality of life in this type of patients, since it can become disabling, thereby increasing alterations in their bio psychosocial environment.

\section{References}

1. César Gotta, Alfredo E. Buzzi y María Victoria Suárez. (2019). Siringomielia y otras etimologías mitológicas., de RAR, volumen 77 ,

2. NA, "Siringomielia", National Institute of Neurological Disorders and strokes, Bethesda, Maryland, 2016, web, revisado en noviembre 2019.

3. Juan Paul Montalvo Herdoiza, Diana victoria Moreira vera; "Evolución natural de la siringomielia: presentación de un caso", reporte de caso clínico". Rev. Ecuat. Neurol. Vol. 26, No 1, 2017, web,
4. J. Giner C. Pérez López, B. Hernández, Á. Gómez de la Riva, A. Islay J. M. Roda (2016) "Siringomielia no secundaria a Chiari. Actualización en fisiopatología y manejo". Servicio de Neurocirugía, Hospital Universitario La Paz, Madrid, Espãna Recibido el 27 de junio de

5. Cedeño W. (2018) "Arnold Chiari tipo I y siringomielia en el adulto". Revista científica INSPILIP V. (21); Numero 1, Guayaquil;

6. Beatriz del Carmen Aguilar Pérez, "manejo de calidad de vida en pacientes con siringomielia en las islas canarias", trabajo de investigacion, universidad de la laguna-sede palma, junio 2017 , web,

7. Pérez Ortiz, Letier, Álvarez Armas, Abel, Rodríguez Ramos, Eglys, \& Laud Rodríguez, Leniel. (2017). Malformación de Chiari Tipo I en adultos. Un enfoque médico-quirúrgico. Parte I. Revista Médica Electrónica, 39(5), 1107-1116. Recuperado en 29 de noviembre de 2019, de

8. Moncho Rodríguez, Dulce María; Poca Pastor, Maria Antònia, dir.; Sahuquillo Barris, Juan, dir. Estudio neurofisiológico mediante potenciales evocados auditivos de tronco cerebral y somatosensoriales en pacientes con malformación de Chiari tipo 1. [Barcelona]: Universitat Autònoma de Barcelona, 2016. 1 recurs electrònic (217 p.). ISBN 9788449068447 . Tesi doctoral Universitat Autònoma de Barcelona. Departament de Cirurgia, 2016
This work is licensed under Creative Commons Attribution 4.0 License
Ready to submit your research? Choose Auctores and benefit from:

* fast, convenient online submission

* rigorous peer review by experienced research in your field

* rapid publication on acceptance

* authors retain copyrights

* unique DOI for all articles

* immediate, unrestricted online access

At Auctores, research is always in progress.

Learn more http://www.auctoresonline.org/journals/neuroscience-andneurological-surger 